\title{
GEOGRAFIA ECONÓMICA DE MANAUS E COMAYAGÜELA: UM ESTUDIO COMPARADO DE ECONOMÍA INFORMAL HONDURENHA E BRASILERA
}

\author{
Kevin Omar Amaya Cocas \\ Mestrando do Programa de Pós-graduação em Geografia - UFAM \\ Universidade Federal do Amazonas \\ Kevin.amaya42@gmail.com \\ Paola Verrí De Santana \\ Professora Doutora do Programa de Pós-graduação em Geografia - UFAM \\ Universidade Federal do Amazonas \\ pvsantana@yahoo.com.br
}

\begin{abstract}
RESUMEN: El siguiente trabajo trae como propuesta realizar un estudio comparativo entre las ciudades de Manaus - AM - Brasil y Comayagüela - MDC- Honduras, cuyo objetivo principal será, analizar cómo está estructurado el sistema económico informal y cuál es la lógica espacial a través del comercio de vía publica en ambas ciudades. Trayendo así una discusión sobre las condiciones de trabajo, en que se desenvuelven estas actividades, ya sean físicas, culturales, políticas, entre otras, dentro del espacio geográfico económico. De esta manera podremos comparar un fenómeno con características heterogéneas partiendo de la hipótesis, en que este fenómeno presentara características diferentes ya que este varía entre diferentes regiones y países de acuerdo con el nivel de desarrollo en la estructura de su economía, dicho estudio será cuantitativo y cualitativo para su entendimiento.
\end{abstract}

Palabras Ilaves: Comercio, Vía Pública, Espacio.

\section{INTRODUCCIÓN}

El siguiente estudio, es resultado de las dudas forjadas gracias a la percepción generada por la cotidianeidad que observada, al tener el privilegio de poder vivir en dos grandes ciudades como lo son Manaus - AM y Tegucigalpa ciudad gemela de Comayagüela MDC (Municipio del Distrito Central).

Donde las condiciones de trabajo se manifiestan de diferente manera, pero que son resultado del mismo sistema explotador, que ha ampliado la brecha de desigualdad social reflejada en la precarización del trabajo, donde las personas no logran obtener las condiciones de lo que es llamado por la OIT de un "Trabajo Decente", siendo orillados a buscar alternativas de inclusión en la estructura social por medio de ocupaciones en condiciones precarias, se trata de las actividades ejercidas en la vía publica conocidas como informales. La economía informal es um fenómeno que está presente en lo cotidiano, muchas veces pasa desapercibida estando en frente de nosotros. Son aquellas actividades desempeñadas por personas que son obligados a luchar por su sobrevivencia en diversas situaciones y adversas condiciones, adaptándose y evolucionan en torno al mundo capitalista que los rodea. 
GEOGRAFIA ECONÓMICA DE MANAUS E COMAYAGÜELA: UM ESTUDIO COMPARADO DE ECONOMÍA INFORMAL HONDURENHA E BRASILERA

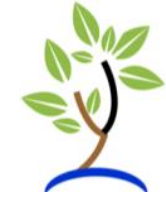

La economía informal puede ser abordada desde diferentes enfoques, desde una perspectiva "jurídica", discutiendo entre lo legal/ilegal, económica dividiendo entre actividades formal/informal, desde un análisis común debatiendo entre lo justo/injusto, desde un aspecto estructural como lo hace OIT/CEPAL, además de diferentes propuestas como las realizadas por Hernando de Soto, Castell e Portes y desde un enfoque geográfico, el cual cabe destacar no es sinónimo de economía informal, es la propuesta por la teoría desarrollada por Milton santos, conocido como "circuito inferior", en su obra sobre el espacio dividido.

Entendiendo de esta manera que la economía informal es um fenómeno amplio, se ha delimitado como objeto de estudio las personas que trabajan en el comercio ambulante, termino el cual ha sido sustituido por vía publica, para evitar su ambigüedad. Este trabajo será realizado desde um enfoque geográfico, para poder complementar la lógica de la distribución y aprovechamiento del espacio por parte de los trabajadores de dicho sector económico, a través de características específicas regionales culturales, donde se desenvuelve la precariedad de condiciones laborales que predomina en estas actividades.

Siendo estos actores de dichas actividades descritos por la OIT como EI comercio en vía pública el cual involucra el comercio propiamente ambulante, el comercio en puesto semi-fijo y en puesto fijo, teniendo como objetivo principal analizar cómo está estructurado el sistema económico informal y cuál es su lógica espacial a través del comercio de vía publica en las ciudades de Manaus - Amazonas - Brasil e Comayagüela- Municipio del Distrito Central - honduras.

Mismos actores a los cuales Milton Santos en su teoría del circuito inferior caracteriza en dos categorías, los que son más o menos sedentarios que tienen su local fijo en la calzada de la calle y los que van en busca de clientes en los barrios.

\section{MATERIALES Y MÉTODOS}

Para entender este fenómeno se hará un levantamiento bibliográfico a partir de diferentes libros, disertaciones, tesis, revistas, consultadas para una exhaustiva exploración en cuanto a la evolución histórica de la economía informal, a partir de estudios realizados a nivel latinoamericano a través de diferentes enfoques, mediante los cuales se han realizado diferentes interpretaciones del fenómeno heterogéneo conocido como economía informal.

\section{RESULTADOS Y DISCUSIÓN}

La economía informal es un fenómeno grande y complejo con características particulares en la forma en que se apropia del espacio, siendo importante destacar que se compone por diferentes sectores, por lo cual será discutido el comercio ambulante y su representación del uso del espacio que este se manifiesta a un nivel 
local, dentro de lo que conocemos como vía pública y su responsabilidad como agente de producción de nuevos espacios de consumo.

Siendo esta manifestación del sector menos privilegiado, una expresión compleja, por ser más que una invasión del suelo, es donde se desenvuelve un complejo mundo de interacciones sociales envueltas entre los diferentes modos de trabajos inseridos en dichos espacios de consumo. Por lo cual la autora Silva apoud OIT (2008, p 28) "señala que el comercio en vía pública y los trabajadores en casa corresponden a los dos grupos más importantes de la fuerza laboral del sector informal".

Siguiendo De Soto (1989, p 69) El término "comercio ambulatorio" evoca dos actividades definidas: "la del comerciante que deambula por la ciudad ofreciendo productos o servicios sin un lugar fijo donde establecerse, y la del comerciante que expende mercadería o presta servicio desde un puesto fijo en la vía pública".

Entendemos que el comercio informal, en lo esencial, se desarrolla en las calles bajo la denominación común del comercio ambulatorio, tornase manifiesta de diferentes formas de apropiación de las calzadas, en lo que conocemos como vía pública. Por lo cual Silva (2008, p 31) apoud OIT propone la siguiente tipología de comerciantes en vía pública:

\begin{abstract}
Los vendedores en la calle no son un grupo homogéneo, pueden ser categorizados o agrupados de acuerdo con: El tipo de bienes que venden, dónde venden y qué medio utilizan para vender, así como su estatus de empleo. Además para algunos es un trabajo de tiempo completo mientras que para otros es de tiempo parcial
\end{abstract}

De acuerdo con la ENE (Encuesta Nacional De Empleo) realizada en México, la cual es destacada por Silva (2008, p 32) en su estudio. El comercio en vía pública involucra el comercio propiamente ambulante, el comercio en puesto semi-fijo y en puesto fijo. Si mismo se apoya en el estudio de Pradilia Cobos, (1993, p. 174). En su estudio sobre el comercio en vía pública en México quien describe

\footnotetext{
"Así pues, la característica principal del comercio en vía pública es su ubicación en los espacios considerados por la legislación vigente como públicos tales como "las vías y circulaciones de automotores y peatones, soportes y medios de transporte público, plazas, parques, bosques, playas y otros lugares"
}

Entendemos así, que las características del comercio en vía púbica estos son definidos por las condiciones de trabajo y el espacio físico donde se establece y reproducen su actividades económicas, Santos en su teoría sobre el circuito inferior hace mención a esta forma de ocupación "Os vendedores de rua constituem o nível inferior da pulverização do comercio, o ultimo elo da cadeia de intermediários entre os importadores, industrias, atacadistas e consumidor". (2008. P 218) 
Podem-se distinguir, grosso modo, duas categorias de vendedores de rua: os que são mais ou menos sedentários, que tem seu local fixo na calcada ou andam com suas mercadorias nas ruas do centro da cidade e aqueles que vão a procura de fregueses nos bairros. (2008. p 219)

Dichas actividades como explica Rodrigo Capelato en su disertación, la cual trae una discusión en torno a la lógica inserida en la propiciación del espacio público conocidos como calzadas donde son construidos los camelos, estudio focalizado a Manaus y la reconfiguración del espacio arquitectónico de la ciudad. Según Capelato $(2008$, p 18) que busca analizar las relaciones sociales dentro del espacio geográfico a partir de la creación de camelos como espacios de consumo modificadores de la estructura urbana.

O Espaço Concreto: corresponde à materialização do espaço através das edificações, dos planos urbanísticos, das áreas de lazer, agregando as formalidades do urbanismo universal, da sociedade ocidental, do capitalismo, do poder do Estado e as contradições estabelecidas nessa tentativa de sobreposição entre o ordenado e o desordenado, o caos e a harmonia, o certo e o errado, o legal e o ilegal.

O Espaço Vivido: corresponde à percepção dos agentes sociais, adequando - Espaço concreto a partir de suas necessidades em uma relação direta com a prática social instaurada.

Espaço Recriado: corresponde a somatória entre o Concreto e o Vivido, suas contradições e suas estratégias de sobrevivência (neste caso, as (re) criações do espaço público pelo comércio de rua).

Entendiendo que existe la necesidad de nuevos estudios a partir de diferentes enfoques para entender cómo se dé desarrolla, manifiesta expande y desaparece la economía informal, teniendo en cuenta que las actividades del comercio de calle presentan realidades y contenidos diferentes en términos de organización de capital y su organización en el espacio.

\section{REFERENCIAS}

CAPELATO, R. "Se essa rua fosse minha..." A (re)criação do espaço público no centro de Manaus. Dissertação de Mestrado - Programa de Pós-Graduação em Sociedade e Cultura na Amazônia da Universidade Federal do Amazonas, Manaus. 2008. 
GEOGRAFIA ECONÓMICA DE MANAUS E
COMAYAGÜELA: UM ESTUDIO COMPARADO DE
ECONOMÍA INFORMAL HONDURENHA
BRASILERA

SILVA, D. Espacio Urbano y Comercio en Vía Pública Reglas, Redes y Uso del Espacio Público en la Ciudad de México, disertación de Maestría en Ciencias Sociales ,FLACSO-Sede Académica México. 2008.

SOTO, H. El Otro Sendero. Bogotá Editorial Printer Colombiana Ltda, 8va Edición. Colombia 1989.

SANTOS, M. O Espaço Dividido: os dois circuitos da economia urbana dos países subdesenvolvidos. Rio de Janeiro, F. Alves, 1979. 